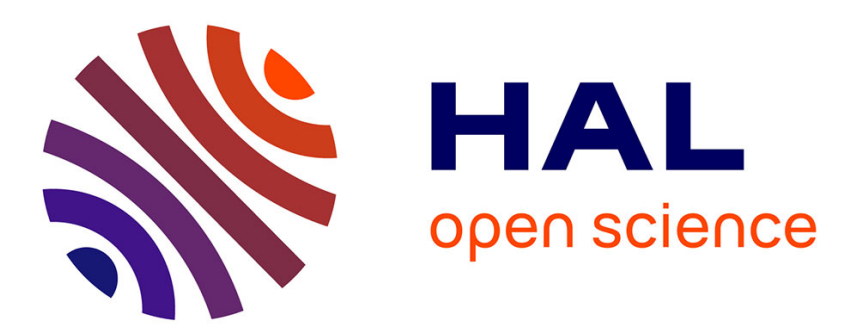

\title{
SITE SELECTIVE SPECTROSCOPY OF Nd3+ AND Cr3+ SITES IN LiNbO3 CRYSTALS CODOPED WITH Mg2+ IONS
}

J. García Solé, A. Monteil, G. Boulon, E. Camarillo, J. Tocho, I. Vergara, F. Jaque

\section{To cite this version:}

J. García Solé, A. Monteil, G . Boulon, E. Camarillo, J. Tocho, et al.. SITE SELECTIVE SPECTROSCOPY OF Nd3+ AND Cr3+ SITES IN LiNbO3 CRYSTALS CODOPED WITH Mg2+ IONS. Journal de Physique IV Proceedings, 1991, 01 (C7), pp.C7-403-C7-406. 10.1051/jp4:19917103 . jpa00250751

\section{HAL Id: jpa-00250751 https://hal.science/jpa-00250751}

Submitted on 1 Jan 1991

HAL is a multi-disciplinary open access archive for the deposit and dissemination of scientific research documents, whether they are published or not. The documents may come from teaching and research institutions in France or abroad, or from public or private research centers.
L'archive ouverte pluridisciplinaire HAL, est destinée au dépôt et à la diffusion de documents scientifiques de niveau recherche, publiés ou non, émanant des établissements d'enseignement et de recherche français ou étrangers, des laboratoires publics ou privés. 


\title{
SITE SELECTIVE SPECTROSCOPY OF $\mathrm{Nd}^{3+}$ AND $\mathrm{Cr}^{3+}$ SITES IN LiNbO CRYSTALS $_{3}$ CODOPED WITH $\mathrm{Mg}^{2+}$ IONS
}

\author{
J. GARCÍA SOLE*,(1), A. MONTEIL*, G. BOULON*, E. CAMARILLO **,(2), \\ J.O. TOCHO**,(3), I. VERGARA** and F. JAQUE** \\ -U.A. C.N.R.S. 442, Université Claude Bernard, Lyon I, F-69622 Villeurbanne, France \\ **Dpto. Física Aplicada C-IV, Universidad Autónoma de Madrid, Cantoblanco, SP-28049 Madrid, \\ Spain
}

Abstract - The fluorescence properties of $\mathrm{Nd}^{3+}$ in $\mathrm{Nd}: \mathrm{MgO}: \mathrm{LiNbO}_{3}$ and $\mathrm{Cr}^{3+}$ in $\mathrm{Cr}: \mathrm{MgO}: \mathrm{LiNbO}_{3}$ systems have been systematically studied after site selective laser excitation. Three kinds of sites have been detected for the active $\left(\mathrm{Nd}^{3+}\right.$ or $\mathrm{Cr}^{3+}$ ) ions. Two sites correspond to the active ion located in $\mathrm{Li}^{+}$and $\mathrm{Nb}^{5+}$ lattice positions, and also appear in the singly (without $\mathrm{MgO}$ ) doped systems. Codoping with $\mathrm{Mg}^{2+}$ ions induce the appearance of a new site for the active ion, together with a decreasing in the $L i / N b$ occupation ratio.

\section{Introduction.}

The understanding of the optical properties of transition metal and rare earth ions in $\mathrm{LiNbO}_{3}$ has gained a considerable interest after demonstration of laser action in miniature and waveguide devices of $\mathrm{Nd}: \mathrm{MgO}: \mathrm{LiNbO}_{3}$ crystals (1,2). These materials appear very promising because they can exploit the laser properties of the active ion together with the non-linear characteristic of $\mathrm{LiNbO}_{3}$, making possible the development of self-frequency doubled lasers. For these applications the addition of about $5 \mathrm{~mol} \%$ of $\mathrm{MgO}$ is necessary to reduce the so called "optical damage", due to the photorefractive effect (3).

Site location of the active ion can play an important role in the optical and laser properties of this ion-host combination. In fact, preliminary studies in $\mathrm{LiNbO}_{3}: \mathrm{Nd}, \mathrm{Mg}$ have shown the formation of a new $N d^{3+}$ site in comparison with the sites appearing in the singly doped system (3).

In this work laser-site selective spectroscopy has been used to study the fluorescence bands of $\mathrm{Nd}^{3+}$ and $\mathrm{Cr}^{3+}$ active ions, which appear in $\mathrm{LiNbO}_{3}: \mathrm{MgO}: \mathrm{Nd}$ and $\mathrm{LiNbO}_{3}: \mathrm{MgO}: \mathrm{Cr}$, respectively. The interest in the last system lies in the possibility of using this material as broadly tunable laser, due to broad emission band of $C r^{3+}$ ion (5). Special emphasis is put in the spectral regions of laser interest.

\section{Experimental.}

The crystals used in this work were grown by Czochralski method. Singly doped crystals had an active ion to Niobium concentration ratio of $0.33 \%$. In doubly doped samples this ratio was $0.15 \%$ and $M g O$ was incorporated in a ratio of $5 \mathrm{~mol} \%$. Samples were cut perpendicular to the c axis.

(1) Permanent address: Departamento de Física Aplicada C-IV, Universidad Autónoma de Madrid, Cantoblanco, SP-28049 Madrid, Spain

(2) Universidad Nacional Autónoma de México, Instituto de Física, P.O. 20364, 01000 México D.F.

(3) Centro de Investigaciones Opticas y Departamento de Física, La Plata, Argentina 


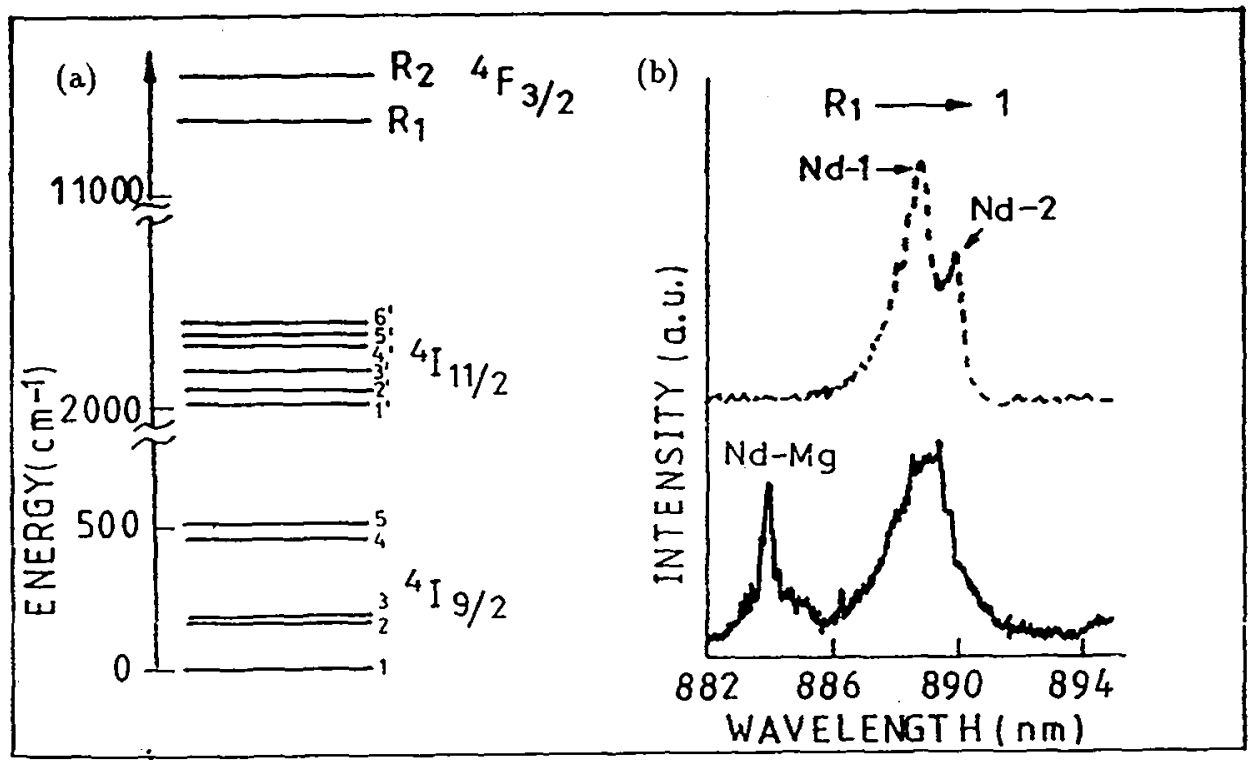

Figure 1: a) Partial energy level diagram for $\mathrm{Nd}^{3+}$ in $\mathrm{LiNbO}_{3}$. b) $R_{1} \rightarrow 1$ emission line for $\mathrm{LiNbO}_{3}: \mathrm{Nd}$ (dashed line), and $\mathrm{LiNbO}_{3}: \mathrm{Nd}, \mathrm{MgO}$ (full line) $(\mathrm{T}: \mathrm{i} 3 \mathrm{~K}$ ).

Emission spectra were excited by laser radiation; $A r^{+}$ion, dye, $N d$ :YAG or Ti:Sapphire lasers. Emitted signal was sent to an EMI-9958-QB photomultiplier or Si-photodiode, depending on the studied spectral region. Resolution was of $1.6 \AA$ in the best cases.

\section{Results.}

The procedure for studying the formation of new active $\left(\mathrm{Nd}^{3+}\right.$ or $\left.\mathrm{Cr}^{3+}\right)$ sites in both $\left(\mathrm{LiNbO}_{3}\right.$ : $\mathrm{Nd}: \mathrm{MgO}$ and $\mathrm{LiNbO}_{3}: \mathrm{Cr}: \mathrm{MgO}$ ) systems has been to compare the fluorescence (excitation and emission) spectra of singly and doubly doped samples.

$\mathrm{LiNbO}_{3}: \mathrm{Nd}, \mathrm{MgO}$

$\overline{N d^{3+}}$ ion presents a rich absorption spectrum due to various transitions between stark en. ergy levels of different terms inside the $4 f^{3}$ configuration of the ion. Figure la shows a partial diagram showing the relevant energy levels responsible for luminescence. The low temperature emission spectrum of this ion consists in two set of lines corresponding to transitions from the low component of the ${ }^{4} F_{3 / 2}$ term to the ${ }^{4} I_{11 / 2}$ and ${ }^{4} I_{9 / 2}$ lower terms. The $R_{1}\left({ }^{4} F_{3 / 2}\right) \rightarrow 1\left({ }^{4} I_{9 / 2}\right)$ line is well isolated in the emission spectrum and can be used for site selective spectroscopy.

Figure $\mathrm{lb}$ shows the $R_{1} \rightarrow \mathrm{l}$ emission spectra, at $10 \mathrm{~K}$, for both singly and doubly doped systems. The peaks denoted as $N d-1$ and $N d-2$ have been previously associated with $N d^{3+}$ ions entering $\mathrm{Ci}^{+}$and $\mathrm{Nb}^{5+}$ lattice sites, respectively (4). In addition the doubly dopes system shows a new $R_{1} \rightarrow 1$ emission band (labelled as $N d-M g$ ) at higher energy, which was associated with the formation of a new $N d^{3+}$ site perturbed by a close $M g^{2+}$ ion. It should be noted as the $N d-1 / N d-2$ ratio for doubly doped samples decreases because of $M g^{2+}$ ions are preferentially entering $\mathrm{Li}^{+}$sites.

Therefore there are three $\mathrm{Nd}^{3+}$ sites in $\mathrm{LiNbO}_{3}: \mathrm{Nd}, \mathrm{Mg}$ with different emission spectra. Figure 2 shows the fluorescence (excitation and emission) spectra of these sites in the spectral 


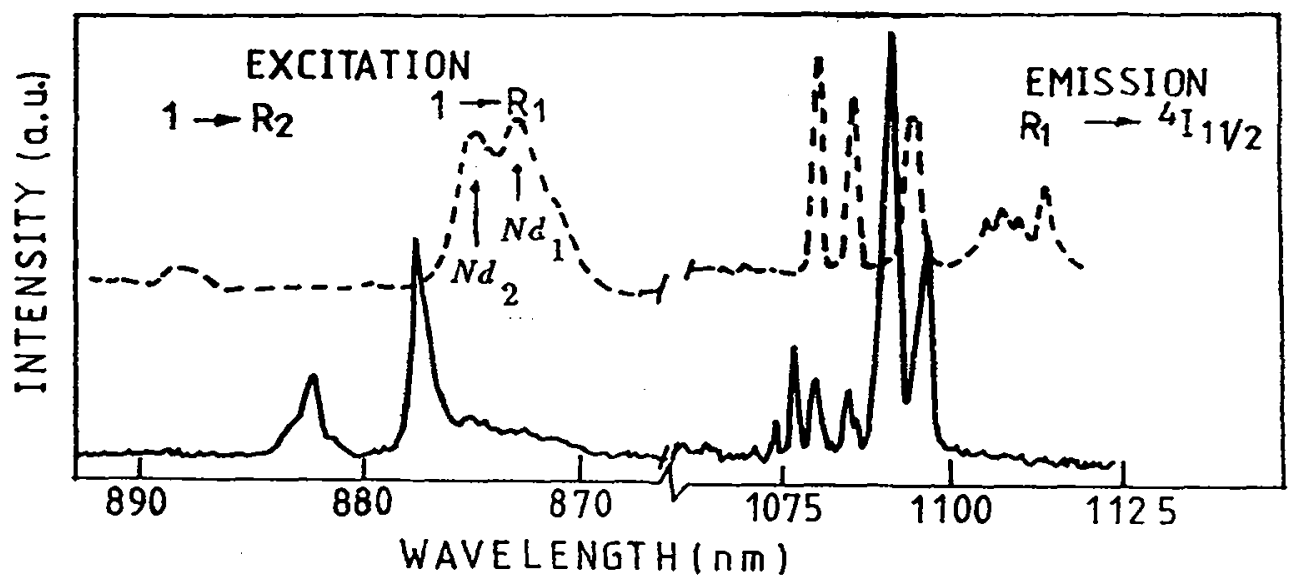

Figure 2: Excitation and emission spectra of $N d-1$ and $N d-2$ (dashed line) and $N d-M g$ (full line) sites, taken on the $\mathrm{LiNbO}_{3}: \mathrm{Nd}, \mathrm{MgO}$ sample $(\mathrm{T}=10 \mathrm{~K})$.

region of interest for laser applications, $R_{1}\left({ }^{4} F_{3 / 2}\right) \rightarrow{ }^{4} I_{11 / 2}$ transitions. The excitation spectrum of the $N d-M g$ site (full line) is well separated from that of $N d-1$ and $N d-2$ sites (dashed line). Therefore $N d-M g$ site can be selectively excited and its $R_{1} \rightarrow{ }^{4} I_{11 / 2}$ emission spectrum appears also shown in figure 2. At rariance, the overlapping between $N d-1$ and $N d-2$ sites leads to emission spectra which can not be completely resolved.

The emission lifetime corresponding to each $N d^{3+}$ site has also been measured giving a value of $95 \mu s$ for $N d-1$ and $N d-2$ sites and being reduced to $75 \mu s$ for new $N d-M g$ site. This result suggests that $N d-M g$ site is emitting more efficiently than $N d-1$ and $N d-2$ sites. On lasing this material, it should be taken into account what center is the responsible for laser action. In fact, this could explain why it is necessary to change the pumping wavelength to get two different laser polarized lines at $1.085 \mu \mathrm{m}$ and $1.093 \mu \mathrm{m}$ in $\mathrm{Nd}: \mathrm{MgO}: \mathrm{LiNbO}_{3}$ miniature lasers (1).

$\mathrm{LiNbO}_{3}: \mathrm{Cr}, \mathrm{MgO}$

The experimental results obtained for the $\mathrm{LiNbO}_{3}: \mathrm{Cr}, \mathrm{Mg}$ systems are similar to the above described using the $N d^{3+}$ ion as active center.

$\mathrm{LiNbO}_{3}: \mathrm{Cr}$ is an intermedial crystal field material (near to the cross-over of $\mathrm{Cr}^{3+}(6)$ ) and then the emission of this ion consists in the ${ }^{4} T_{2} \rightarrow{ }^{4} A_{2}$ broad luminescence, useful for tunability, and the ${ }^{2} E \rightarrow{ }^{4} A_{2}$ sharp emission.

Figure 3 shows the emission spectra for the singly (dashed line) and doubly doped (full line) crystals under excitation with light into the ${ }^{4} T_{1} \rightarrow{ }^{4} A_{2}$ broad band. The ${ }^{4} T_{2} \rightarrow{ }^{4} A_{2}$ vibronic emission band (useful for tunability) is slightly different for both systems, the peak position being shifted to lower energies for the $\mathrm{Cr}: \mathrm{MgO}: \mathrm{LiNbO}_{3}$. However the best information on multisites can be obtained from the ${ }^{2} E \rightarrow{ }^{4} A_{2}$ sharp emission. This transition, which appears split in two components labelled as $R_{1}$ and $R_{2}$ in order of decreasing energy, is very sensitive ic slight changes in the local enviroment. The main ${ }^{2} E \rightarrow{ }^{4} A_{2}$ peaks have been associated (7) with the $R_{1}$ emission of $\mathrm{Cr}-1\left(\mathrm{Li}^{+}\right)$and $\mathrm{Cr}-2\left(\mathrm{Nb}^{5+}\right)$ sites. The small peak at higher energy is the $R_{2}$ emission peak of the $\mathrm{Cr}-1\left(\mathrm{Li}^{+}\right)$site. As in the $\mathrm{LiNbO}_{3}: \mathrm{Nd}, \mathrm{Mg}$ system, codoping with $M g^{2+}$ ions induces the appearance of two new peaks which are the $R_{1}$ and $R_{2}$ components of a new $\mathrm{Cr}^{3+}$ center, induced by the proximity of $M g^{2+}$ ions. This new site has been denoted as $\mathrm{Cr}-\mathrm{Mg}$ site. 


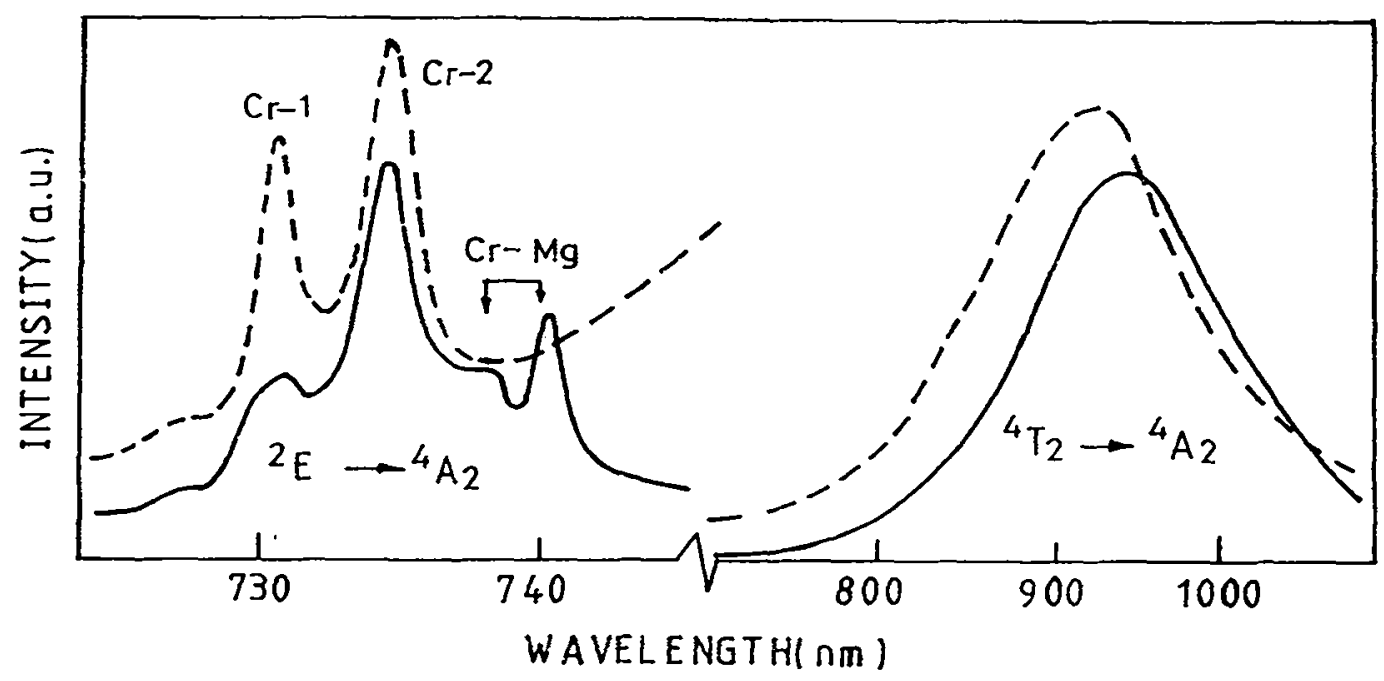

Figure 3: Emission spectra (10 K) of $\mathrm{LiNbO}_{3}: \mathrm{Cr}$ (dashed line) and $\mathrm{LiNbO}_{3}: \mathrm{Cr}, \mathrm{MgO}$ (full line) samples.

Lifetime of the ${ }^{4} T_{2} \rightarrow{ }^{4} A_{2}$ vibronic emission changes from $10 \mu \mathrm{s}$ for the singly doped crystal to $17 \mu \mathrm{s}$ for the doubly doped one. The lifetime of the $R_{1}$ emissions are $400 \mu s$ for $C r-1$ and $C r-2$ sites, and $500 \mu s$ for $C r-M g$ site. This variation can be explained by considering spin orbit admixing between the ${ }^{4} T_{2}$ and ${ }^{2} E$ levels as in the case of $C r$ doped garnets (8).

Finally, we have to mention that the effect of adding $\mathrm{Mg}^{2+}$ ions to the $\mathrm{Cr}$ doped $\mathrm{LiNbO}_{3}$ also affect the absorption spectrum of $C r^{3+}$ shifting the ${ }^{4} A_{2} \rightarrow{ }^{4} T_{1}$ and ${ }^{4} A_{2} \rightarrow{ }^{4} T_{2}$ vibronics bands to the red. This results explain why the green single crystals become pink after codoping with $M g^{2+}$ ions.

\section{References.}

1. A. Cordova-Plaza. M.J.F. Digonnet and H.J. Shaw, IEEE J. Quantum Electron., QE-23 (1987) 262.

2. E. Lallier, J.P. Pocholle, M. Papuchon, M. de Micheli, M.J. Li, Q. He, D.B. Ostrowsky, C. Grezes-Besset and E. Pelletier, Opt. Lett. 15 (12) (1990) 682.

3. D.A. Brian, R. Gerson and H.E. Tomaschek, Appl. Phys. Lett. 44(a) (1984) 847.

4. G. Lifante, F. Cussó, F. Jaque, J.A. Sanz-García, A. Monteil, B. Varrel, G. Boulon and J. Garcia Solé, Chem. Phys. Lett. 176 (1991) 482.

5. V.G. Babadjanyan, E.P. Kokanyan, R.B. Kostanyan and V.R. Kikogosyan, Opt. Comm. $78(3,4)(1990) 247$.

6. P.F. Moulton in "Tunable paramagnetic-ion lasers". Laser Handbook vol.5 edited by M. Bass and M.L. Stitch. North-Holland (1985).

7. W. Jia, H. Liu, R. Knutson, W.M. Yen, Phys. Rev. B, 41 (6) (1990) 1096.

8. B. Struve, G. Huber, Apply. Phys. B 36 (1985) 195. 